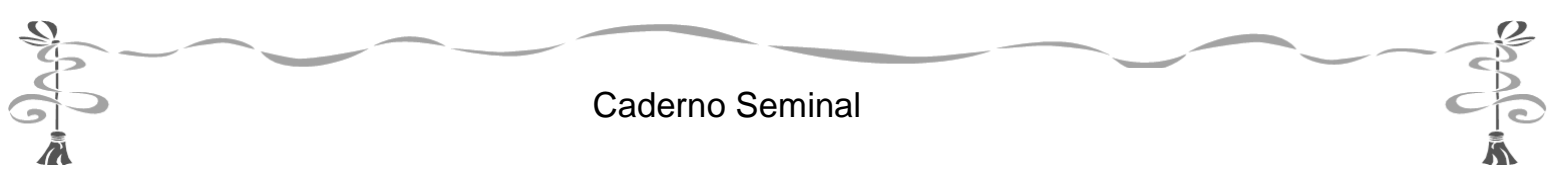

\title{
LÍNGUA PORTUGUESA COMO SEGUNDA LÍNGUA PARA ALUNOS SURDOS: PROPOSTAS DE ATIVIDADES A PARTIR DE INTERFACES TECNOLÓGICAS
}

\author{
PORTUGUESE AS A SECOND LANGUAGE FOR DEAF STUDENTS: PROPOSALS FOR \\ ACTIVITIES BASED ON TECHNOLOGICAL INTERFACES
}

Maria Clara M. A. Ribeiro ${ }^{46}$

\section{Resumo}

Este trabalho objetiva refletir sobre as possibilidades do uso e aplicação de Tecnologias da Informação e Comunicação no processo de ensino-aprendizagem de português (escrito) como segunda língua para alunos surdos. Apresentaremos propostas de atividades que privilegiam a interação surdo/surdo em português escrito por meio de interfaces tecnológicas. Os resultados indicam que o uso de tecnologias nas aulas de línguas torna as aulas mais dinâmicas e motivadoras e possibilitam o exercício do letramento de maneira efetiva, através da interação escrita, de surdo para surdo.

Palavras-chave: Tecnologia; Ensino de Língua Portuguesa; Surdos.

\section{Abstract}

This work aims to reflect on the possibilities of the use and application of Information and Communication Technologies in teaching Portuguese as a second language for deaf students. The activities presented emphasize the interaction deaf to deaf in written Portuguese based in technological interfaces. The results indicate that the use of technology makes the lessons more dynamic and motivating, enabling the exercise of literacy effectively through deaf to deaf written interaction.

Key word: Technology; Language Teaching; Deaf.

\section{Considerações Iniciais}

O objetivo deste estudo é refletir sobre os usos e possibilidades da aplicação de Tecnologias da Informação e Comunicação (TICs) no ensino da língua portuguesa (LP) a alunos surdos. Apresentaremos, primeiramente, o panorama linguístico-social em que os surdos se inserem atualmente, uma vez que para se preservar a identidade linguístico-cultural de alunos bilíngues e para propor atividades que a tomem como aliada, é preciso, antes de tudo, conhecê-la. Em seguida, refletiremos sobre o uso de TICs na educação, evidenciando a nossa perspectiva de trabalho nesse campo. Por fim, serão apresentadas propostas de atividades que visem o exercício do letramento em LP.

\footnotetext{
${ }^{46}$ Doutoranda no programa de pós-graduação em Estudos Linguísticos pela UFMG. UFMG/FAPEMIG - mclaramaciel@ hotmail.com
}

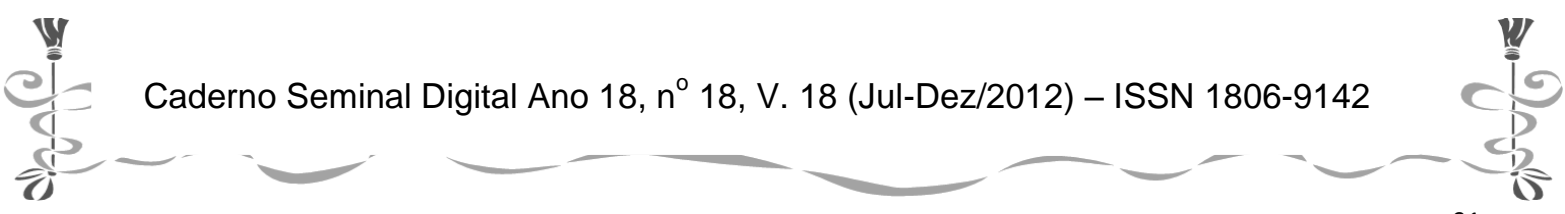




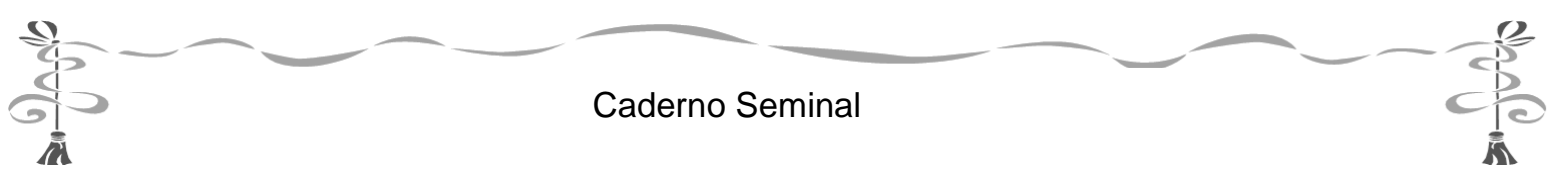

Os discursos sobre a surdez vêm se movimentando e alterando ao longo do tempo. Certamente, falar de sujeitos surdos, hoje, não é o mesmo que falar deles há quinze, dez ou cinco anos passados.

Atualmente, em vários lugares do mundo, surgem Movimentos político-sociais, liderados e constituídos por surdos - e por representantes da academia - em prol do reconhecimento das línguas de modalidade vísuo-espacial e da cultura surda, assim como dos valores e direitos dessa população. E enquanto muitos surdos se esforçam para serem "normais", fazendo uso de próteses auditivas, terapias fonoaudiológicas e convivendo apenas com ouvintes, o grupo que se organiza em torno do chamado Movimento Surdo se descobre mantenedor se uma organização linguístico-cultural minoritária, que questiona a norma ao sentir orgulho da surdez, rejeitando de vez o estigma da "deficiência" (RIBEIRO; LARA, 2010).

Enquanto isso, na academia, assistimos ao surgimento de um novo campo teórico: os Estudos Surdos ${ }^{47}$, área a partir da qual os surdos são compreendidos nas ciências humanas, onde, diferentemente do campo da saúde, o valor da diferença sobrepuja o da deficiência.

Toda essa movimentação social e teórica produz efeitos na forma de ensinar e de aprender. Hoje, sabemos: para se educar sujeitos surdos, a abordagem deve ser distinta da abordagem assistencialista da educação especial, por um lado, e também distinta do efeito placebo da educação dita inclusiva, por outro (SOUZA; GÓES, 1999; CAMPELO, 2009). A abordagem desejada parte da possibilidade de uma educação bilíngue, que leve em consideração as especificidades históricas, linguísticas, culturais e identitárias do povo surdo. Em outras palavras: atualmente, espera-se uma abordagem própria, específica e exclusiva ao público surdo, que parta de uma chamada pedagogia surda.

Diante de tudo isso, os surdos são considerados, na contemporaneidade, uma minoria linguística culturalmente estabelecida, não mais sujeitos portadores de uma necessidade especial (SKLIAR, 1999; SOUZA; GOES, 1999; MOURA, 2000; SÁ, 2006). Avanços acadêmico-científicos contribuíram sobremaneira para essa mudança de paradigma, ao constatarem que: (a) os surdos se utilizam de uma língua genuína, natural e multiarticulada, com gramática própria, equiparável às línguas orais em complexidade, como relatam Quadros; Karnopp (2004) e Lodi (2004); (b) a surdez, em si mesma, não acarreta déficit linguístico ou cognitivo. É possível ao ser humano desenvolver-se com plenitude em um mundo alheio a audição, conforme indicam Souza (1998) e Bernardino (1999), uma vez que a faculdade da linguagem pode ser exercida por diferentes modalidades de línguas (tanto oral-auditiva, quanto

\footnotetext{
47 Os Estudos Surdos são compreendidos como uma área interdisciplinar de estudos que tem como grande área os Estudos Culturais e a Educação. Skliar (1998, p. 5) o define como "um programa de pesquisa em educação, onde as identidades, as línguas, os projetos educacionais, a história, a arte, as comunidades e as culturas surdas são focalizados e entendidos a partir da diferença, a partir de seu reconhecimento político".
}

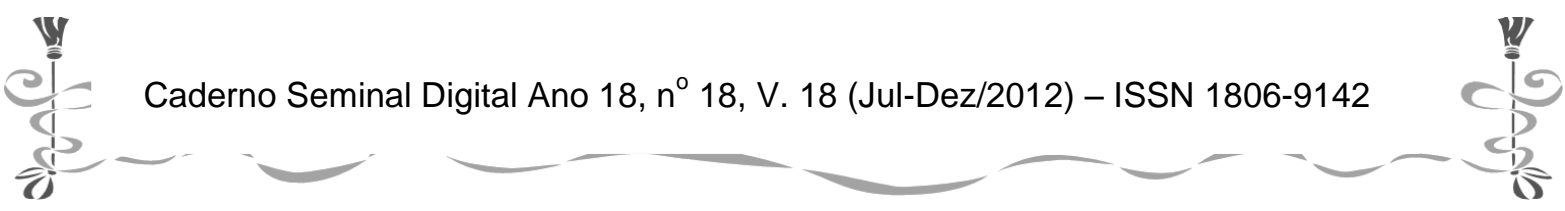




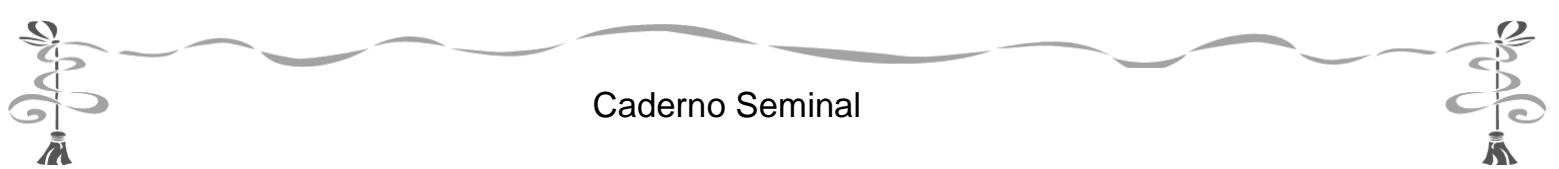

vísuo-espacial); (c) as línguas de sinais, no caso do Brasil, a Língua Brasileira de Sinais (Libras), devem ser consideradas línguas maternas (L1) para os surdos ${ }^{48}$, conforme explica Quadros (1998); (d) a língua oral majoritária no país, no caso do Brasil, a língua portuguesa, deve ser considerada a segunda língua (L2) dos surdos, devendo ser ensinada a partir de metodologias de ensino de segunda língua e recebendo o status de língua estrangeira ${ }^{49}$, como defende Brochado (2006); e) na escola, é preciso abordar exclusivamente habilidades de leitura e escrita, uma vez que habilidades como compreensão ou fala não são nem necessárias nem bemquistas, como informa Capovilla (2000).

Partimos dos princípios acima para refletir, neste estudo, sobre o uso de tecnologias no ensino de línguas para surdos. Como se pôde perceber, surdos são cidadãos brasileiros, usuários "nativos" da Libras e aprendizes de português como segunda língua - uma minoria linguística ainda não completamente compreendida em suas especificidades e direitos linguísticos. Portanto, o ensino de português para essa população se restringirá ao ensino da leitura e da escrita da língua, o que aumenta a complexidade do processo.

Para ilustrar, imaginemo-nos aprendendo a língua russa, por exemplo, apenas a partir da leitura e da escrita dessa língua. No caso dos estudantes surdos, há agravantes adicionais, uma vez que nós, ouvintes, temos internalizadas hipóteses sobre o funcionamento de línguas orais e partimos de uma base de alguma maneira semelhante para realizar transferências de habilidades linguísticas da língua fonte (português) para a língua alvo (no caso, russo). Surdos, no entanto, partem cognitivamente do funcionamento de línguas visuais, que apesar de certamente compartilharem de universais linguísticos comuns, estabelecem relações (espaciais) bastante distintas das ocorridas nas línguas orais (fonoarticulatórias).

O resultado de toda essa complexidade transparece na escrita desses sujeitos, que costuma ser compreendida como atípica, errônea ou peculiar. Góes (1996), por exemplo, relata que mesmo após anos de escolarização, surdos continuam apresentando dificuldades no uso da escrita da Língua Portuguesa (LP).

Referindo-se a surdos usuários da Língua Inglesa, Koutsoubou (2000) aponta um quadro semelhante, destacando que a maioria dos estudantes surdos sai da escola com um grau de letramento equivalente ao terceiro ou quarto ano de educação escolar (TURNER, 2000 apud KOUTSOUBOU, 2000). De acordo com os padrões ingleses de avaliação de letramento, habilidades inferiores aos níveis estabelecidos

\footnotetext{
48 Justificando: a Libras é a língua possível e natural aos surdos. É ela que possibilita aos sujeitos organizarem pensamentos completos e elaborados. Será através dela que eles poderão lançar mão de habilidades criativas e recursivas no campo da língua e daí resulta o seu estatuto de primeira língua, independente da ordem de aquisição linguística das línguas (libras e português). 49

9 Neste trabalho, os conceitos de segunda língua e língua estrangeira estão sendo utilizados indistintamente.
}

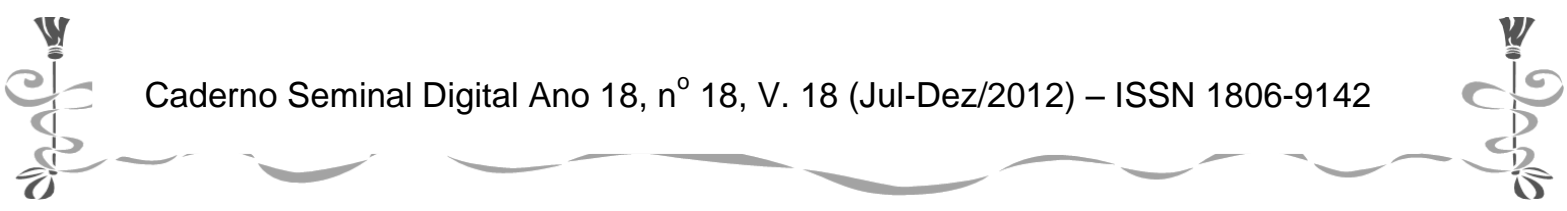




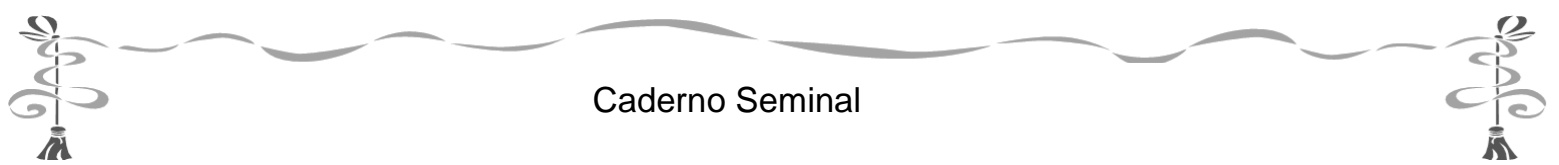

para o quarto ano de educação escolar representam um analfabetismo funcional (ALBERTINI, 1993 apud KOUTSOUBOU, 2000).

Diante de tudo isso, justifica-se a pertinência de oportunizar a vivência da LP escrita em situações de interação, de surdo para surdo, a partir da tecnologia.

\section{Sobre o uso de tecnologias na educação}

Certamente, a tecnologia modifica algumas dimensões da nossa inter-relação com o universo social, com o tempo e o espaço e com os objetos cognoscentes. A tecnologia está em nossas vidas, mas não necessariamente na relação que estabelecemos com a construção de conhecimentos formais.

No trabalho com a tecnologia na esfera educacional, é tarefa do professor apresentar aos alunos as possibilidades e limites desse "novo" mundo que desponta. O professor pode conduzir a inserção de tecnologias na educação de diferentes maneiras e é justamente o direcionamento dado por ele que irá definir o valor e as especificidades desse trabalho.

É importante alertar, de início, que a inserção de tecnologias da informação não deve ser considerada apenas como um instrumento ou uma ferramenta utilizada na execução de tarefas já conhecidas, como produzir textos, por exemplo, como defende Marques Neto (2007, p. 61). De maneira análoga, deter o foco no produto (que se atinge com as tecnologias), deixando o processo desfocado, também não produz bons resultados e não condiz com a filosofia que deveria alicerçar o trabalho com tecnologia na educação.

No trabalho com tecnologia, a nosso ver, é preciso privilegiar o processo, a construção, as interações efetivas e as criações. A máquina não pode silenciar os alunos, tampouco os professores. Ao contrário, tem de gerar diálogo, debate, interação, criação, autonomia e emancipação.

Se definirmos "as tecnologias como conjuntos de dispositivos técnicos que apresentam uma linguagem própria e que estabelecem uma relação pragmática com seus usuários", como define Beloni (2003, p. 61), podemos ver, com clareza, em alguns momentos, o desejo de primazia da técnica sobre outros processos socioeducacionais. É isso o que queremos? Certamente, não. Lion (2007) nos lembra de que não criamos inovações pedagógicas na escola somente por incorporar novos meios (tecnológicos), ferramentas ou instrumentos. A tecnologia, em si mesma, não é nem boa nem má. A concepção do enfoque apropriado dependerá de uma mudança de abordagem fundamental, que deve ser priorizada pelo professor: se os alunos passarem de meros usuários/receptores a gestores/produtores (seja de tecnologia, de opinião ou de sua própria aprendizagem) começaremos a ter indícios de um trabalho benéfico, que prioriza a autonomia e a emancipação crítica dos aprendizes.

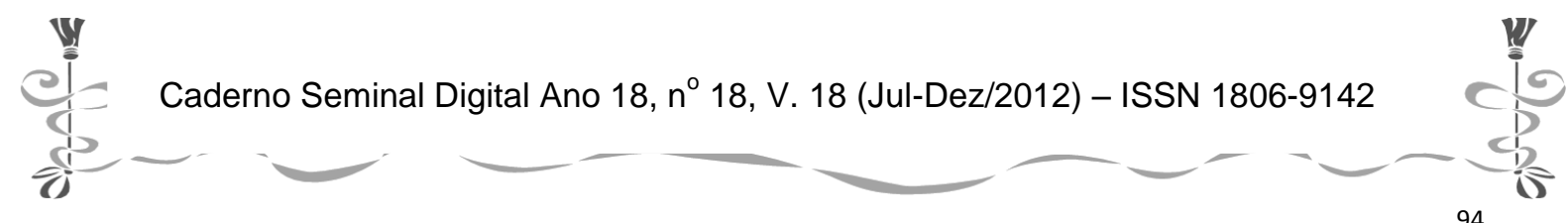




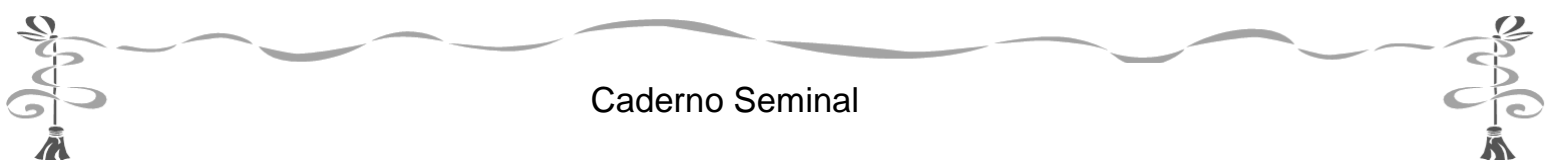

Como se nota, não nos filiamos a uma ideologia tecnocrata, mas vislumbramos, com criticidade, a riqueza de possibilidades que podem ser atingidas a partir do ensino de línguas para surdos aliado à tecnologia. Portanto, não é demais lembrar: educativos e interativos somos nós, máquinas são apenas máquinas. É o direcionamento dado pelo professor que produzirá (ou não) interatividade e promoção do saber.

De acordo com Vieira e Moura (2009), a aprendizagem colaborativa, proporcionada pela interação em dada comunidade de aprendizagem virtual, além de produzir autonomia, potencializa o desempenho dos aprendizes, uma vez que

a colaboração pressupõe uma tarefa mútua na qual os parceiros trabalham em conjunto para produzir algo que nenhum deles poderia ter produzido individualmente. Dentro de um ambiente computacional, a interação entre pares, permeada pela linguagem (humana e da máquina), potencializa o desempenho intelectual porque força os indivíduos a reconhecer e coordenar perspectivas conflitantes de um problema, construindo um novo conhecimento a partir de seu nível de competência que está sendo desenvolvido dentro e sob a influência de um determinado contexto histórico-cultural (VIEIRA; MOURA, 2009, p. 15).

No tocante ao uso de interfaces tecnológicas no ensino de português para surdos, há boas evidências de que o tempo de exposição dos aprendizes à língua alvo (português) será maximizado, se comparado ao ensino comum, além de estendido em espaços e tempos distintos dos da sala de aula. Há como hipótese que essas ferramentas podem aproximar os sujeitos da cultura letrada, possibilitando o exercício do letramento de maneira efetiva, uma vez que, em sala de aula, a interlocução se estabelece em Libras e o tempo destinado à leitura e escrita se mostra reduzido.

Para ilustrar, pensemos em uma sala de aula onde se ensina inglês como língua estrangeira. Um professor comum procuraria estabelecer, em inglês, o máximo de interação verbal possível com seus alunos. Comandos, cumprimentos e pequenos diálogos seriam estabelecidos na língua alvo, como forma de aproximar o ambiente da sala de aula de um ambiente de imersão linguística propriamente dita. No caso de professores de português para surdos, no entanto, priorizar a interação na língua alvo não é possível. Os motivos podem ser facilmente elencados: os alunos aprendem mais e melhor em Libras; uma gama de significantes do PT é desconhecida por muitos alunos; a interação escrita não pode ser exaustiva, para não se tornar monótona ou com excessos de episódios de interincompreensão, que acabam por desmotivar os alunos. Essa questão será abordada adiante.

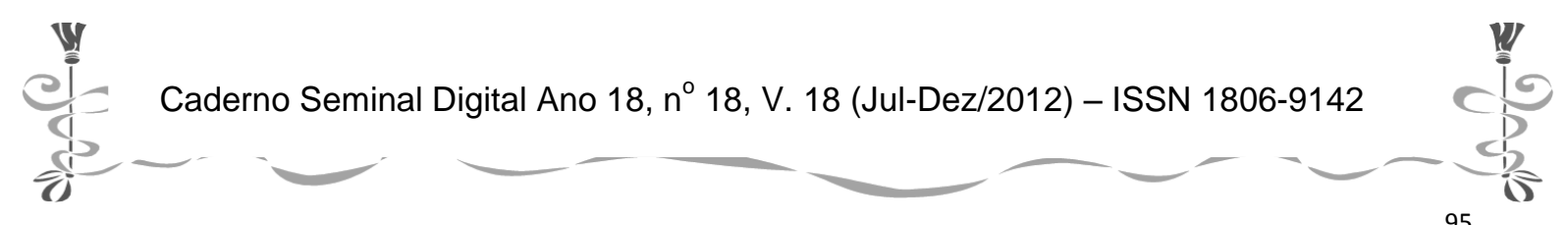




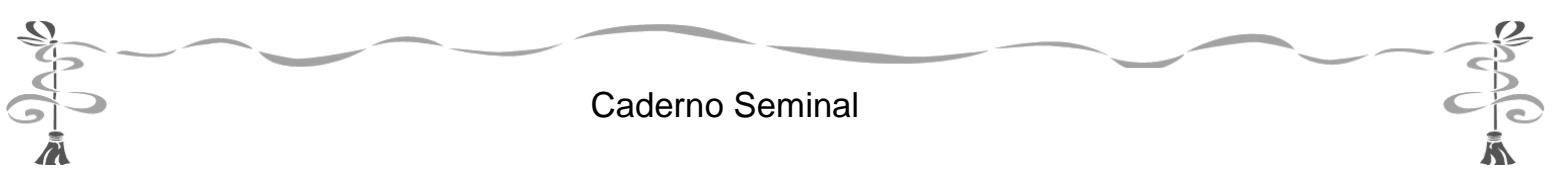

É importante lembrar ainda que a tecnologia parece fazer parte do acervo cultural da comunidade surda. Desde os antigos aparelhos TDD $^{50}$ até as campainhas que acionam luzes, os despertadores vibratórios e os mais recentes softwares de tradução Libras/português (e vice-versa), observamos a tecnologia aliada à melhoria de vida desses sujeitos. Curiosamente, a informática tem sido considerada por muitos professores como uma das áreas de melhor desempenho escolar dos surdos. Além disso, atualmente, inúmeros surdos brasileiros têm a oportunidade de realizar cursos de graduação em Letras/Libras (licenciatura e bacharelado), à distância, ofertados gratuitamente pela Universidade Federal de Santa Catarina.

Isso nos leva a pensar que cursos de língua de curta duração/atualização/extensão oferecidos à distância teriam boa receptividade na comunidade surda e isso aumentaria as chances de êxito educacional dessa população. Ou, mais especificamente, nos levam a pensar que a escola inclusiva, tão duramente rotulada de ineficiente no tocante ao ensino de línguas para surdos, pode ter na tecnologia um aliado de valor.

\section{Tecnologias e estratégias de ensino de línguas para alunos surdos}

Qual é o objetivo maior que se espera atingir quando se ensina línguas estrangeiras a alunos surdos? Os objetivos, em sentido lato, não diferem substancialmente dos objetivos gerais do ensino de línguas para ouvintes: almeja-se desenvolver nos aprendizes uma competência comunicativa que os possibilite a interagir na língua alvo. Em sentido estrito, contudo, podem-se prever objetivos distintos, específicos ao ensino de línguas para surdos, uma vez que habilidades como "fala e compreensão" não serão requeridas, por um lado, e que habilidades como leitura e escrita, por outro, tomarão uma dimensão totalizante.

Pensando no ensino de português para surdos, de forma geral (e sucinta), espera-se: (i) tornar o aluno apto tanto à leitura (compreensão e interpretação) de diferentes gêneros textuais, quanto à escrita (também de diferentes gêneros), onde se priorizarão habilidades de coerência e coesão textual. E de forma específica, esperase ainda: (i.i) que ele internalize ${ }^{51}$ as estruturas morfossintáticas e modo-temporais da língua portuguesa (i.ii) que seja capaz de perceber as diferenças estruturais entre a Libras e o português (i.iii) que o aluno se torne letrado em português, isto é, capaz de realizar com autonomia atividades de leitura e escrita no seu dia-a-dia como mais uma de suas práticas sociais.

\footnotetext{
${ }^{50}$ TDD (Telecommunications Device for the Deaf) é um sistema de comunicação telefônica digital onde os surdos podem se comunicar escrevendo mensagens em um teclado e visualizando em uma tela as mensagens que lhe são enviadas e recebidas. 0 advento dos celulares com editores de texto, que possibilitam o envio de mensagens (SMS), tem mostrado que o TTD, com o tempo, se tornará peça de museu.

51 Uma vez que em Libras, de maneira ampla, flexões verbais e marcações modo-temporais não apresentam formas desinenciais, tais processos se tornam complexos para os aprendizes de PTL2. Não se espera, portanto, um saber consciente, mas um saber prático, ainda que inconsciente.
}

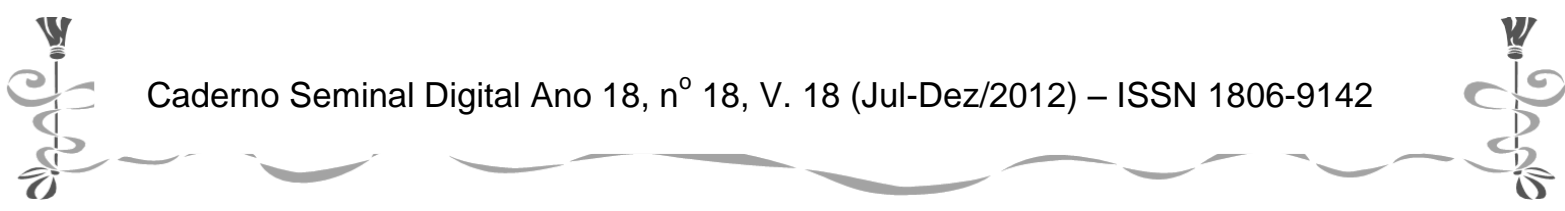




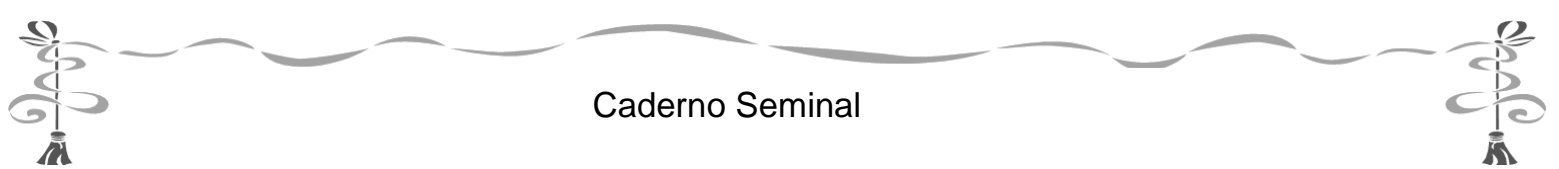

Mas como se deve ensinar uma língua de modalidade oral-auditiva a alunos surdos? Será através da Libras? Será através exclusivamente do português, para criar um ambiente de imersão? Ora, a segunda opção, sabemos, não pode ser válida! Não haveria imersão, uma vez que os surdos perderiam todas as informações orais e auditivas. E seria possível haver imersão através, exclusivamente, da modalidade escrita? Também sabemos que não. Como seria possível se, muitos surdos, desconhecem uma vastidão de significantes em português? Explicamos: ocorre, muitas vezes, de os significados estarem construídos em Libras, com seus respectivos significantes e, no entanto, os surdos desconhecerem os significantes que designam, em português, o significado previamente construído em sinais. É como se escrevêssemos a palavra respeito, por exemplo, na louça, e os surdos nos dissessem: “não sei o que é isso!". Um professor inexperiente poderia, sem intenção, ser levado a construir ideias preconceituosas e hostis aos surdos diante desse fato, mas o professor experiente saberia do que trata: ele faria o sinal de respeito em Libras e mostraria que, e em português, aquele é o significante do significado respeito.

Dessa maneira, como se vê, não seria nem possível nem proveitoso ensinar português para surdos por intermédio do próprio português, uma vez que esta língua nada intermediaria.

O decreto 5.626, de 2005, garante aos surdos brasileiros a possibilidade de receberem uma educação bilíngue, onde o conteúdo escolar esteja acessível também em Libras, por meio da inserção de professores bilíngues ou de Tradutoresintérpretes de línguas de sinais no ambiente escolar (opção mais comum no Brasil). O que se mostra apropriado e grandemente proveitoso, então, é: ter a Libras como língua de instrução, tanto nas aulas de português, quanto de inglês, matemática ou história. As razões são tão óbvias que evitaremos delongas.

O que fazer, diante disso, para ensinar português para surdos, através da Libras, mas criando e otimizando ao máximo o tempo de exposição do aluno ao português? Como vimos, não é possível que o professor chegue diante de seus alunos e não sinalize, ou pouco sinalize, apenas enchendo a lousa. Isso não produziria aprendizagem e deixaria os alunos extremamente tensos e frustrados. Qual seria, então, uma solução possível? Através do uso de tecnologias, ou para sermos mais específicos, através da educação à distância e do uso das TICs. Pensaremos, então, no uso das TICs no ensino de línguas para surdos, tanto na modalidade presencial quanto na modalidade à distância.

\section{Possibilidades das TICS no ensino presencial e na educação à distância}

Temos percebido cada vez mais que educação à distância e ensino presencial não são polos opostos, mas, ao contrário, contínuos em uma mesma reta. Como mencionado, o uso de TICs no ensino presencial pode ser visto como uma ferramenta pedagógica que promove interação e aprendizagem colaborativa. A partir

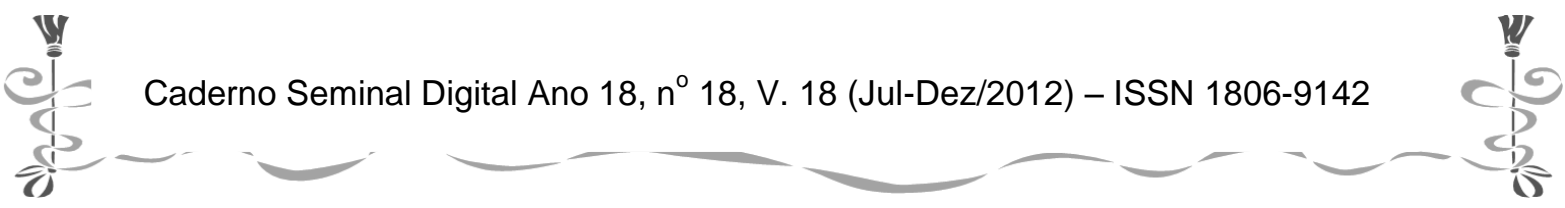




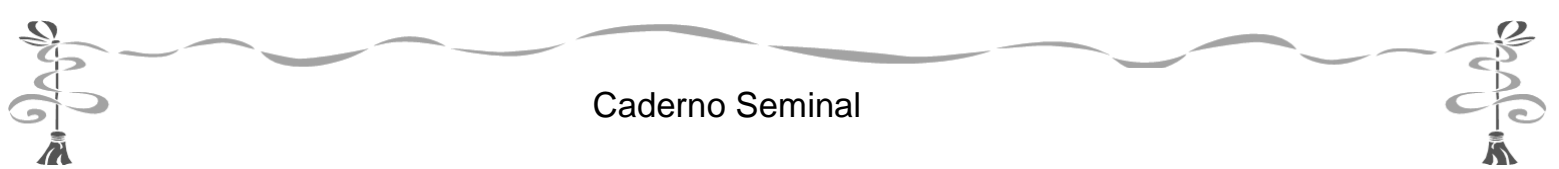

daí, as significativas mudanças na forma de se pensar o processo educativo pode ser observado, pois o que se pretende é construir uma rede de aprendizagem colaborativa que tire o foco do professor e o coloque nas interações entre os aprendizes e na autonomia conferida por esse processo.

É possível pensar que o uso das TICS, no ensino presencial, possibilita, com efeito, a combinação da educaşão à distância e da educação presencial. Esta possibilidade produz efeitos muito positivos, visto que a partir dessa mescla as aulas se tornam mais dinâmicas e, dada à inserção das TICs, no tocante a alunos surdos, vê-se o exercício do letramento (em português escrito) de maneira efetiva. A vantagem da mescla de modalidades é que o professor pode mediar, em Libras (pessoalmente ou por intermédio de um tradutor-intérprete), olho no olho, todas as discussões ou construções concebidas a partir das TICS - possibilidade que seria reduzida no ensino exclusivamente à distância. Não se pode negar que as aplicações dessas ferramentas no ensino presencial são extensas e profícuas.

É possível pensar ainda nas TICS no ensino a distância. $\mathrm{Na}$ modalidade exclusivamente à distância, os sujeitos surdos deverão ter estímulos ou incentivos extras, uma vez que pouco espaço será reservado à instrução em Libras, fato que pode não apenas dificultar a comunicação como causar desestímulos aos sujeitos. Esses estímulos podem ser compreendidos, sobretudo, como estímulos visuais, como a exploração de imagens e esquemas, uma versão colorida do ambiente, brilhos e formas inusitadas, por exemplo, etc.

Em segundo lugar, é preciso prever que pouco espaço para a Libras não significa nenhum espaço! Em um curso de línguas para surdos, na modalidade à distância, teremos de reservar tempo e espaço para a produção de vídeos didáticos em Libras ou até mesmo para o desenvolvimento de softwares que possibilitem que, ao clicar sobre uma palavra desconhecida, um vídeo abra com a imagem do sinal correspondente em Libras. Isso nos mostra que, certamente, para o desenvolvimento desses recursos, será preciso algumas "inovações" na forma padrão de se fazer educação à distância.

A videoconferência, por exemplo, apresentará, certamente, um caráter primordial e mais usual, se comparado ao padrão dos cursos à distância projetados para ouvintes. O chat, talvez, poderia virar uma espécie de MSN, com a possibilidade de inserção de vídeo.

Voltando ao ensino presencial e pensando na sala de aula inclusiva, aliar interfaces tecnológicas ao ensino de línguas para surdos pode resolver uma parte dos inúmeros problemas surgidos pela inclusão de alunos surdos (usuários de Libras) em um ambiente de educação linguística predominantemente ouvintista, ou melhor, voltado para alunos ouvintes (usuários nativos da língua portuguesa).

Explicando melhor: ouvintes, na escola, aprendem LP como língua materna. Surdos, no entanto, devem aprender como segunda língua, a partir de conteúdos e

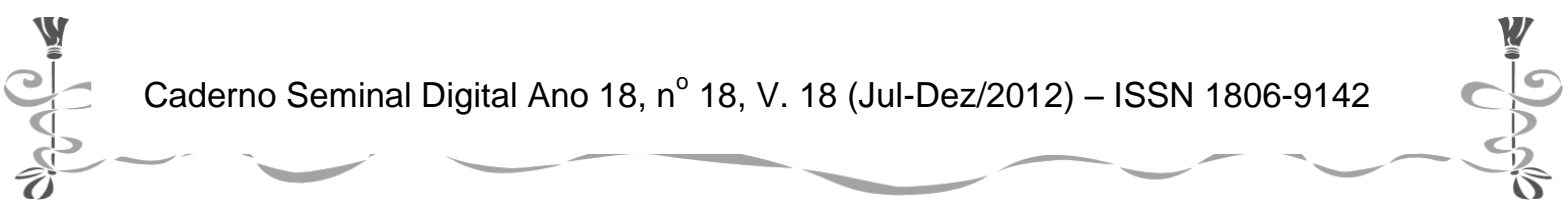




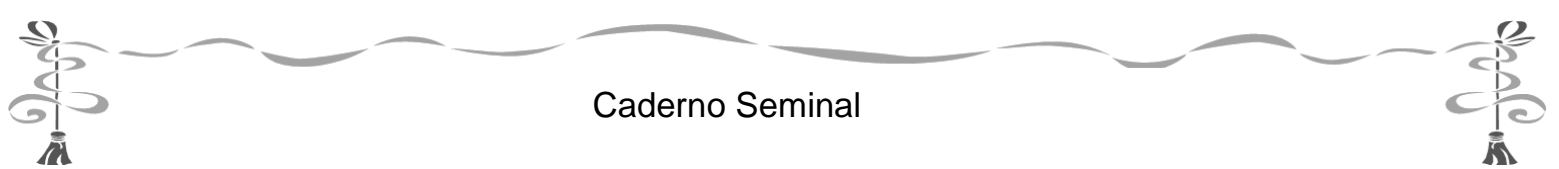

metodologias de ensino de português como língua estrangeira, pois, como se sabe, a Libras é a língua materna desses sujeitos. No entanto, não é essa realidade observada. O que resulta disso é a insatistação e desinteresse da maioria dos alunos e a descrença do professor no trabalho que desenvolve (SILVA; PEREIRA, 2003; GONÇALVES, 2012).

Se pensarmos, por exemplo, no currículo do $9^{\circ}$ ano do ensino fundamental, veremos que os professores de LP estarão privilegiando, em algum momento, o estudo das diversas categorias de orações reduzidas. Ora, certamente, um aluno surdo comum estará, nessa fase, começando a solidificar suas hipóteses acerca da ordem básica dos constituintes frasais na língua portuguesa (em Libras, verifica-se uma organização sintática extremamente maleável) e internalizando um complexo sistema de conjugações verbais (de certo ponto de vista, inexistente em Libras). Para equalizar, de alguma maneira, questões problemáticas como essa, podem ser possível abrir uma "frente de trabalho" outra, on-line, com os alunos surdos, onde a língua portuguesa fosse ensinada a partir de metodologias de ensino de língua estrangeira. Isso poderia ser altamente vantajoso para as escolas inclusivas.

A seguir, apresentaremos interfaces e propostas de atividades ainda não testadas formalmente, mas já projetadas e vislumbradas como possíveis e promissoras. Essas atividades estão em vias de implementação no Laboratório Experimental de Ensino de Línguas para Surdos ${ }^{52}$ e os resultados dessa experiência serão temas de estudos outros - desenvolvidos por nós ou por demais professores que virem na nossa proposta um caminho possível. O nosso objetivo, aqui, portanto, é oferecer um leque de possibilidades para professores de surdos e desencadear uma rede de ação e reflexão a partir dele. Alertamos que as propostas e atividades a seguir não são os planos de aula ou receitas a serem seguidas, mas guias conceituais na construção de atividades que busquem promover o letramento de surdos em português escrito.

\section{Blog: discussões de interesse político-social, que envolvam o desenvolvimento de uma ética-cidadã.}

O blog tem sido definido como uma "página de Internet com características de diário, atualizada regularmente" ${ }^{53}$. Trata-se do registro (de tema delimitado) postado na internet e organizado de forma cronológica. No caso dos alunos surdos, o uso do blog coletivo, como ferramenta pedagógica, propicia a exposição e compartilhamento de ideias na língua alvo a partir da exploração de um tema de interesse comum. O blog pode ser criado com o objetivo de divulgar ou difundir dada conquista ou característica do povo surdo, por exemplo. A primeira lição aqui,

\footnotetext{
${ }^{52}$ Projeto de pesquisa e extensão vinculado ao Departamento de Comunicação e Letras da Universidade Estadual de Montes Claros, cujo objetivo é desenvolver estratégias de ensino de línguas para surdos.

${ }^{53}$ Dicionário Priberam da Língua Portuguesa. Disponível em: http://www.priberam.pt/DLPO/default.aspx?pal=blogue
}

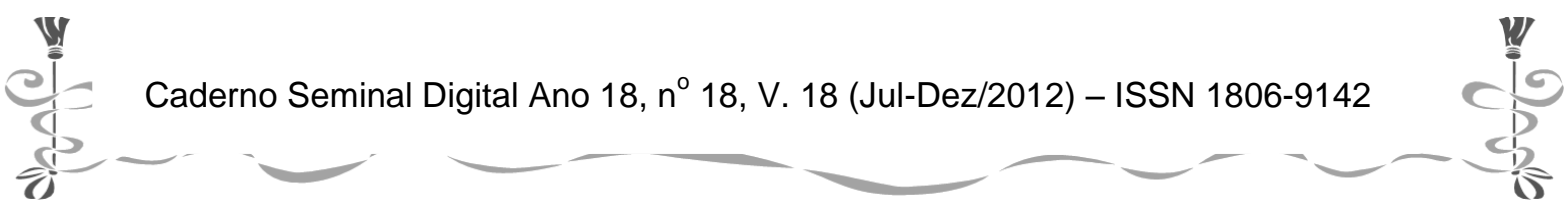




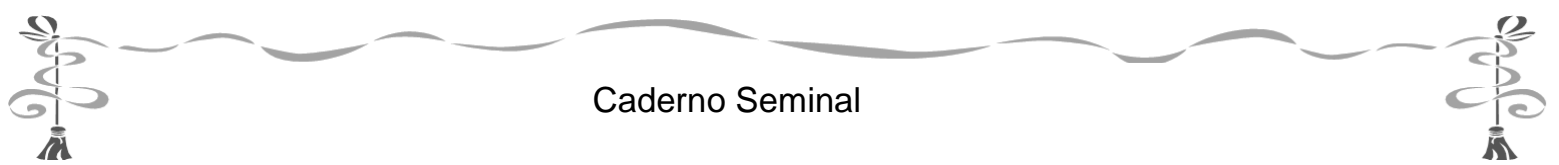

para os alunos, é entender que todo texto projeta um leitor modelo, e que eles serão lidos (e, portanto, necessitam ser compreendidos) por muitos.

Esta atividade propõe a criação de um blog coletivo a ser criado e mantido pelos alunos. É importante que a temática seja motivadora e, em alguma medida, polêmica. Sugere-se que o tema envolva discussões de interesse político-social e que visem o desenvolvimento de uma ética-cidadã. Poder-se-ia tratar de alguma reivindicação política das comunidades surdas, de questões ecológicas que envolvam a cidade, ou de algum mote fornecido por uma notícia local.

Nessa atividade, os alunos devem se entender exclusivamente através da leitura e da escrita, mas tudo será esclarecido e/ou aprofundado na sala de aula presencial, em sinais. O professor pode, por exemplo, pedir para que cada um explicite, em sinais, a leitura que fez do texto do colega para poder, assim, corrigir interpretações equivocadas. Pode, ainda, se utilizar de padrões errôneos repetitivos na escrita dos alunos para inferir sobre a natureza do erro: trata-se de influência da estrutura da Libras? Trata-se de desconhecimento de uma estrutura específica do português? Essas hipóteses seriam construídas pelo professor em parceria com seus alunos. Em segundo momento, poder-se-ia propor que os alunos postem novos textos no blog, registrando as discussões estabelecidas em sala de aula e fazendo uso das novas estruturas linguísticas que aprenderam.

Antes do início dessa atividade, recomenda-se que o professor debata em sinais o tema a ser abordado com os seus alunos, para prepará-los e motivá-los para a atividade que virá. Desenvolver um mural sobre o tema, em conjunto com os alunos, se mostra proveitoso na medida em que fornece suporte visual e temático para os participantes.

\section{Fórum: debate de textos estéticos ou utilitários.}

Uma explicação simplista do fórum o definiria como uma atividade de discussão assincrônica entre os sujeitos participantes. Nessa atividade, os alunos surdos interagem em português escrito e devem procurar estabelecer uma espécie de diálogo ou de continuação responsiva com os posts anteriores: a habilidade de leitura será, aqui, tanto requerida quanto desenvolvida. Esta atividade desenvolve a competência comunicativa e responsiva e encoraja os alunos a interagirem uns com os outros através da LP.

De início, o professor pode postar um texto para leitura (uma notícia curta, por exemplo), acompanhado de uma questão elementar de compreensão textual. Ele deve intervir, dando o opinião da questão e apresentando reflexões e outras questões que fomentem/direcionem o debate. Sugere-se, por exemplo, que o professor direcione questões a alunos específicos ou aproxime comentários semelhantes e/ou antagônicos, colocando os alunos em debate.

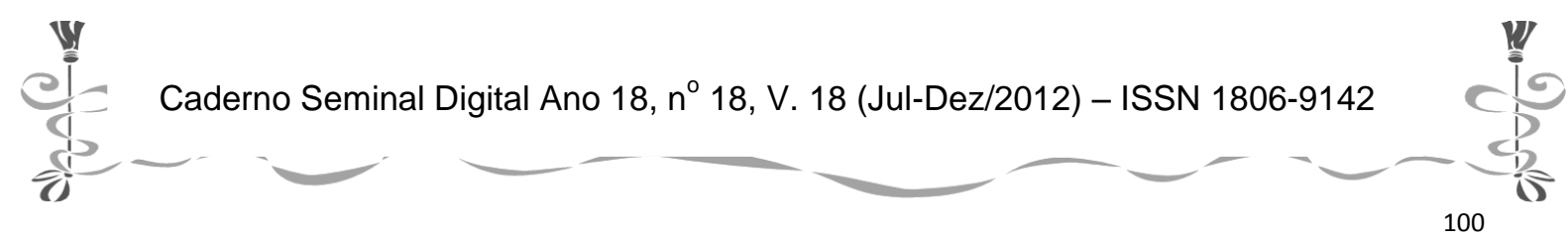




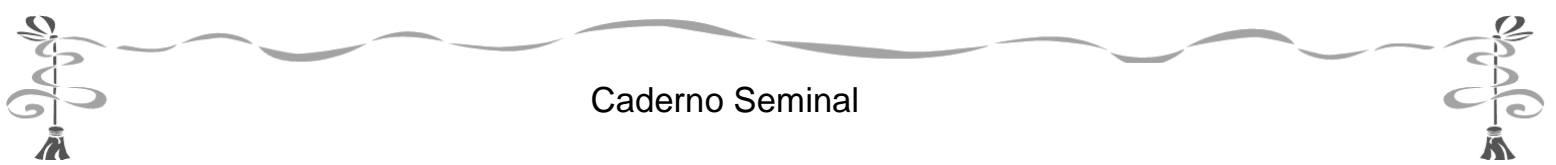

Se possibilidade técnica houver, o professor pode, em alguns fóruns, corrigir alguns textos, inserindo abaixo do texto original o texto corrigido. Tal fazer, contudo, precisa ser cercado de cuidados e bom senso, pois correções em demasia, além de desnecessárias, prejudicam a fluidez e espontaneidade dos alunos. O ideal é que se corrijam poucos posts (de alunos diferentes), que contenham erros significativos e repetitivos.

Além de trabalhar com textos estéticos (literários) ou utilitários (instrucionais ou jornalísticos, por exemplo), o professor poderá também trabalhar com textos metalinguísticos, ou seja, textos que tenham a língua (ou o fazer comunicativo) como objeto. Assim, discussões seriam travadas sobre a língua a partir do exercício do uso da língua.

É fundamental que o professor de português para surdos conheça a Libras em algum grau de profundidade. Isso será importante no momento de interagir em português escrito com os seus alunos, pois o professor deverá se utilizar de uma linguagem simples e clara e preferencialmente (pelo menos no início) a partir de um vocabulário considerado comum em Libras. O conhecimento da Libras será fundamental ainda no momento de compreensão da escrita dos alunos e na análise da natureza dos erros.

\section{Wiki: produção de textos coletivos.}

Certamente, o exemplo mais conhecido dessa interface é, sem dúvidas, a enciclopédia virtual Wikipédia, que permite a edição coletiva dos textos que a compõem. De maneira semelhante, propõe-se que os alunos desenvolvam um texto a partir de uma escrita coletiva, "zigzagueante", com possibilidades de edição e reedição a todo o momento.

Nesta atividade, os alunos desenvolverão a capacidade de explorar e refletir sobre o texto do outro, além da possibilidade de se posicionar, pelo menos uma vez, como o sujeito que detém o poder da correção, em uma manifestação de empoderamento.

A sugestão para essa atividade é que os alunos construam coletivamente uma narrativa ficcional, em Libras, e que aos poucos a registrem e complementem em português escrito, coletivamente, no wiki. Piadas, estórias de terror ou recontos literários estão entre os gêneros preferidos pelos alunos. A tarefa do professor, nessa atividade, é direcionar a produção, alertando para os processos e etapas comuns a uma narrativa, por exemplo. É importante que o professor não tente "higienizar" o plano de expressão textual da escrita de seus alunos, com correções em excesso, mas que permita a manifestação das singularidades e eventuais equívocos da escrita surda em busca de um bem maior: a riqueza e coerência do plano de conteúdo. Após o fim da atividade, os alunos terão produzido um texto que, mais adiante, poderá ser retomado pelo professor, em conjunto com os alunos-produtores, em uma atividade

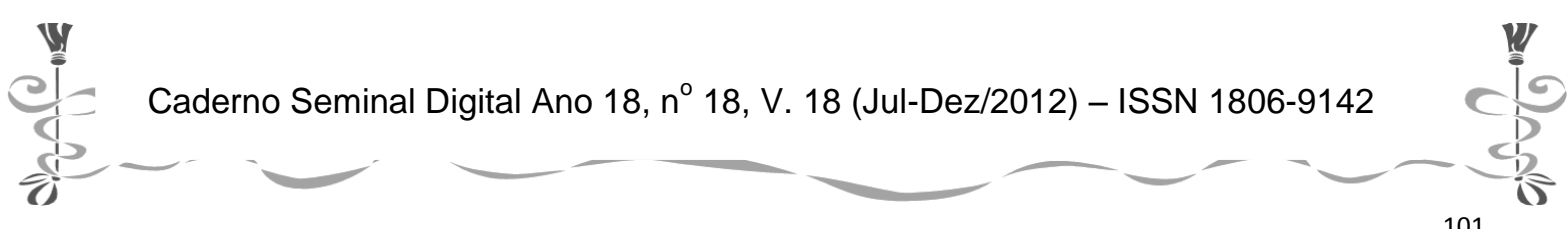




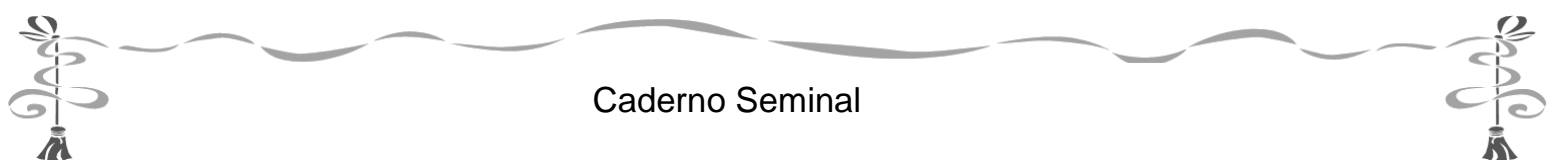

de reescrita coordenada pelo mestre, isto é, oportunamente, poderá lançar mão desse material para corrigi-lo coletivamente, em parceria com os seus alunos.

\section{Legendagem e produção visual: narrativas em Libras e PT}

Esta atividade destaca a importância da língua fonte no processo de aprendizagem da língua alvo e pode ser considerada uma das atividades mais bem recebidas pelos alunos.

Trata-se da realização de uma produção visual, com diálogos em Libras, e inserção de legendas em português, criado, dirigido e editado pelos alunos. A produção pode ser fictícia, como um curta-metragem, com enredo, personagens, tempo e espaço definidos, ou pode ser um documentário, com debates e opiniões sobre temas da atualidade ou de interesse comum. A escolha do gênero a ser produzido será determinada pelo perfil da turma.

Para o desenvolvimento da atividade, o professor deverá gerenciar a divisão de grupos e a distribuição de papeis em cada um deles: roteiristas, cinegrafista, atores, diretores e editores estão entre as categorias principais. Sugere-se que a função de roteirista seja atribuída a mais de um sujeito. O professor deverá orientá-los quanto à importância do planejamento dessa etapa da produção e encorajá-los a ouvir o restante do grupo na determinação da temática.

Para a elaboração das legendas, o grupo não poderá ser desmembrado, pois elas deverão ser debatidas de maneira coletiva (grupal) e realizadas na sala de aula. É possível dividir o vídeo em tomadas e determinar um editor principal para a inserção de legendas em cada uma delas, desde que o texto em português nasça da coletividade e seja fruto de debate.

Para a inserção de legendas, há softwares leves, gratuitos e de fácil acesso disponíveis na internet. Depois de pronta, é possível convidar um professor surdo para assistir à produção e comentar a tradução. Esta atividade trás a vantagem de explicitar aos alunos as diferenças e semelhanças entre a Libras e o Português.

\section{Considerações finais}

O trabalho com tecnologias no ensino de línguas para surdos mostra-se promissor. É difícil pensar, em pleno século XXI, no desenvolvimento de processos de ensinoaprendizagem totalmente alheios à tecnologia. Se o uso das TICs não acontecer de maneira formal, sob a orientação de professores qualificados para tal, certamente acontecerá de maneira descompromissada, pois sabemos da relação que as novas gerações mantêm com elas. O que propomos, então, é que a educação se aproprie de algo que já está nas mãos dos alunos, dando um direcionamento pedagógico e explorando facetas não visadas no uso informal.

Neste estudo, enumeramos algumas possibilidades de utilização das TICs no ensino de português para alunos surdos. O nosso intuito foi demonstrar que o ensino de

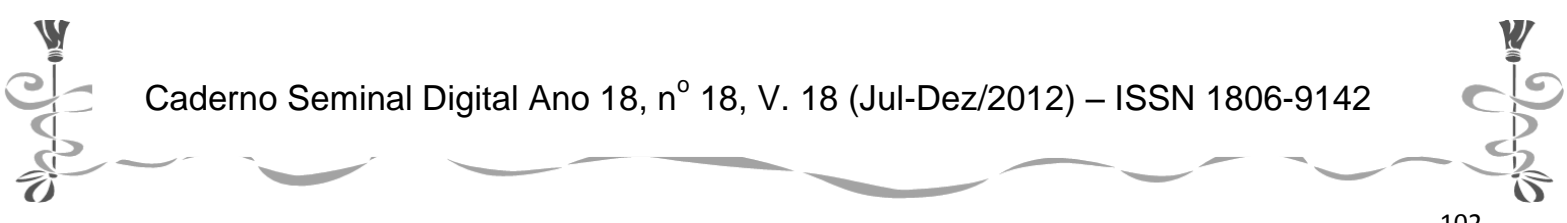




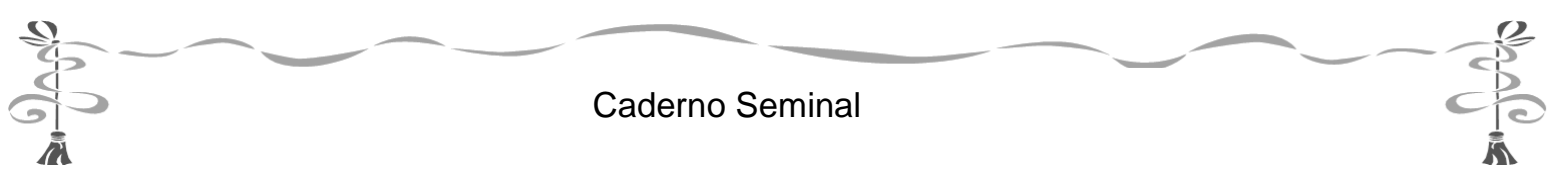

português para surdos pode e precisa extrapolar o domínio físico da sala de aula. Principalmente quando nos damos conta de que, na sala de aula inclusiva, os alunos surdos aprendem o português como a língua materna e que o professor regente da sala inclusiva ou da sala de recursos deverá lançar mão de estratégias outras para atingir seus objetivos (ensinar LP como L2).

O futuro dominado por parafernálias tecnológicas parece ter chegado. O direcionamento e tratamento adequado de tudo isso, no entanto, está em nossas mãos. Façamos, portanto, boas escolhas.

\section{Referências}

BELLONI, M. L. A integração das tecnologias de informação e comunicação aos processos educacionais. In: BARRETO, R. G (org.). Tecnologias educacionais e educação à distância: avaliando políticas e práticas. Rio de Janeiro: Quartet, 2a ed. 2003. p. 54 - 73

BERNARDINO, E. L. Absurdo ou Lógica? Os surdos e sua produção linguística. Belo Horizonte, Editora Profetizando a Vida, 2000.

BROCHADO, S. M. D. A apropriação da escrita por crianças surdas usuárias da língua de sinais brasileira. 2003. 439 f. Tese de Doutorado (Letras). Faculdade de Letras, UNESP, Assis, 2003.

CAMPELO, A. R. S. A pedagogia visual na educação dos surdos-mudos. 2008. 245 f. Tese de doutorado (Educação). Faculdade de Educação, UFSC, Santa Catarina.

CAPOVILLA, F. C. Filosofias educacionais em relação ao surdo: do oralismo à comunicação total e ao bilinguismo. Revista Brasileira de Educação Especial. Marília, SP, v. 6, n. 1, p. 2000. 99-116, Disponível em: L/www.abpee.net/homepageabpee04 06/artigos em pdf/revista6numero1pdf/r6 art06.pdf

FONSECA, J. J. S. da. Educação à distância: potencialidades e vulnerabilidades. In: VII Encontro de Pesquisadores da UECE, 2001, Fortaleza. Anais (CD) do VII Encontro de Pesquisadores da UECE, 2001.

GONÇALVES, A. G. Sobre o ensino de Libras e de Português na escola inclusiva: a perspectiva dos alunos envolvidos. 2012. Trabalho de Conclusão de Curso (Especialização em Linguística). Faculdade de Letras, Universidade Estadual de Montes Claros.

KOUTSOUBOU, M. Deaf ways of writing narratives: a bilingual approach. In: RIJLAARSDAM, G.; BERGH, H.; COUZIJN, M. (eds.). Effective learning and teaching of writing. A handbook of writing in education. E-book. Disponível em http://www.scribd.com/doc/35338635/Effective-L-T-Writing. Acesso: dezembro de 2011.

LION, C. G. Mitos e realidade na tecnologia educacional. In: LITWIN, Edith (Org.). Tecnologia Educacional: política, história e propostas. Porto Alegre: Artes Médicas, 1997. p. 23 36.

LODI, A. C. B. Uma leitura enunciativa da Língua Brasileira de Sinais: o gênero contos de fadas. DELTA. Documentação de Estudos em Linguística Teórica e Aplicada, São Paulo, v. 20, n. 2, 2004, p. 281-310.

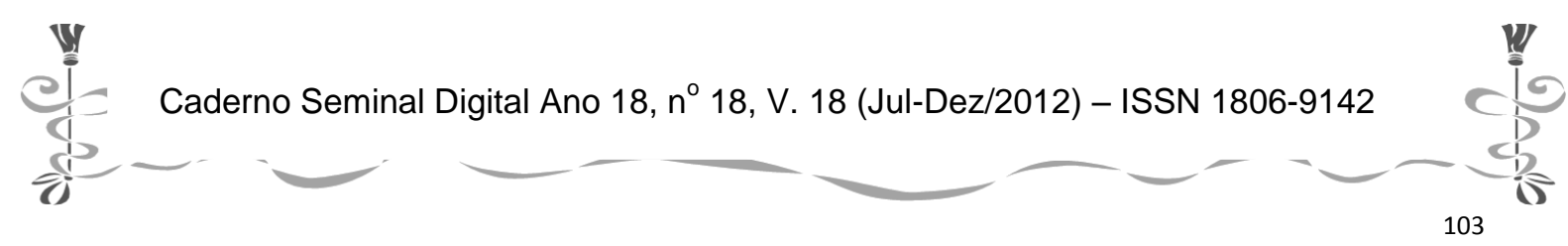




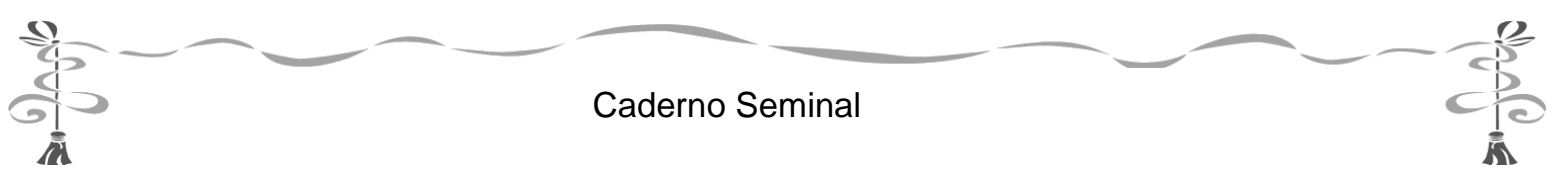

MARQUES NETO, H. T. A tecnologia da informação na escola. COSCARELLI, C. V. Novas tecnologias, novos textos, novas formas de pensar. 3. ed. Belo Horizonte: Autêntica, 2006. p. $51-64$

MOURA, M.C. O surdo: caminhos para uma nova identidade. Rio de Janeiro: Revinter, 2000.

QUADROS, R. M. Educaşão de surdos: a aquisição da linguagem. 1. ed. Porto Alegre: Artes Médicas, 1997.

QUADROS, R. M.; KARNOPP, L. B. Lingua de sinais brasileira: estudos linguísticos. ArtMed: Porto Alegre, 2004.

SÁ, N. L. Cultura, poder e educação de surdos. São Paulo: Paulinas, 2006.

SILVA, A. B. P.; PEREIRA, M. C. C. O aluno Surdo na escola regular. Imagem e ação do professor. Psicologia: Teoria e Pesquisa, vol. 19 n. 2, pp. 173-176, 2003. Disponível em http://www.scielo.br/pdf/ptp/v19n2/a10v19n2.pdf. Acesso: janeiro de 2012.

SKLIAR, C. B. Um olhar sobre o nosso olhar acerca da surdez e das diferenças. In: SKLIAR, C (org.). A surdę: um olhar sobre as diferenças. Porto Alegre: Mediação, 1998.

SKLIAR, C. B. Os estudos surdos em educação: problematizando a anormalidade. In: $A$ surdeæ: um olhar sobre as diferenças. Porto Alegre: Mediação, 1998.

SOUZA. R. M. de. Que palavra que te falta? Linguística, educação e surdez: considerações epistemológicas a partir da surdez. São Paulo: Martins Fontes, 1998.

SOUZA, R. M.; GÓES, M.C.R. O ensino de surdos na escola inclusiva: considerações sobre o excludente contexto da inclusão. In: SKLIAR, C. B. (Org.). Atualidades da educação bilíngue para surdos, V.1. Porto Alegre: Mediação, 1999.

VIEIRA, F. M. S; MORAES, R. de A. O uso do computador como recurso didático. In: VIEIRA, F. M. S.; SANTOS, D. P. (Org.). Mídias na Educação: Experiências na UNIMONTES. 1 ed. Montes Claros: UNIMONTES, 2009, v. 1, p. 9-25.

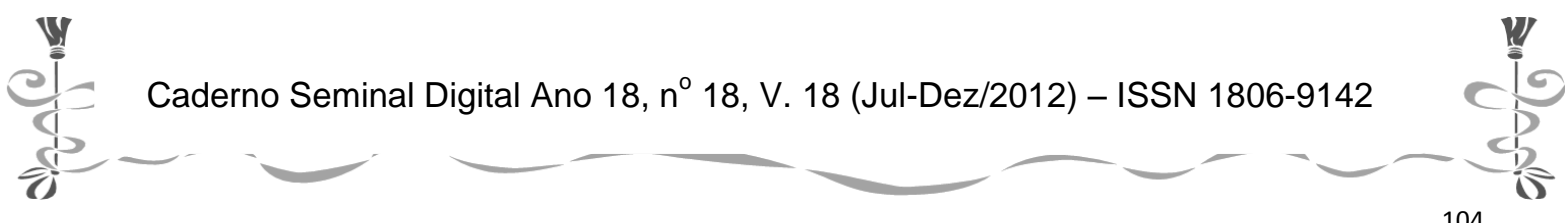

